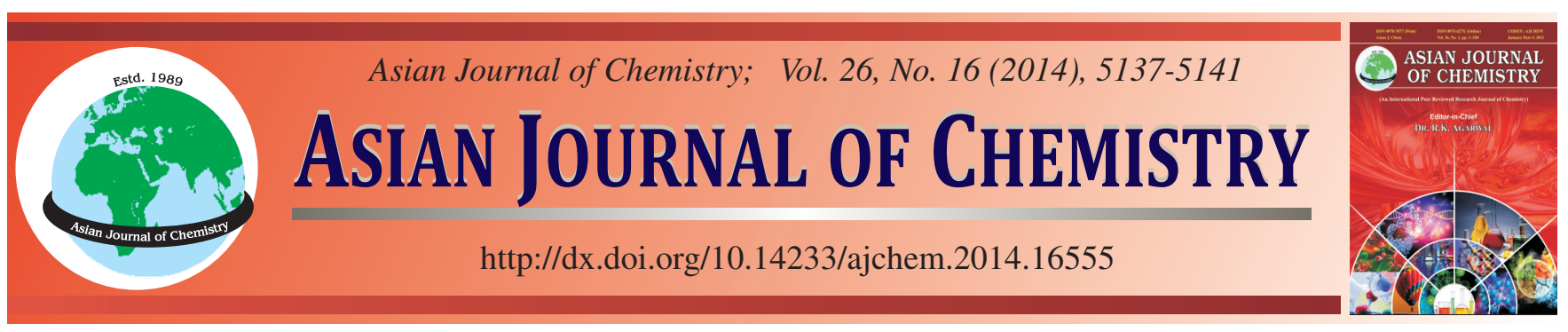

\title{
Biosorption of Lead(II) by Endophytes EPL01 of High Arsenic Resistance Isolated from Hyperaccumulator Plant Pteris cretica
}

\author{
Kai Yu ${ }^{1,2}$, Yiting Luo $^{1}$, Ruizhi Dong ${ }^{1}$, FAng Deng $^{1, *}$ and Xinman Tu ${ }^{1}$
}

${ }^{1}$ Key Laboratory of Jiangxi Province for Persistent Pollutants Control and Resources Recycle, Nanchang Hangkong University, Nanchang 330063, P.R. China

${ }^{2}$ Institute of Wastes and Soil Environment, Shanghai Academy of Environmental Sciences, Shanghai 200233, P.R. China

*Corresponding author: E-mail: dengfang40030@126.com

A novel endophyte L01 (EPL01) with high adsorption capacity for lead(II) was isolated from arsenic hyperaccumulator Pteris cretica and identified to be a Bacillus sp.. The adsorption isotherm of lead(II) on EPL01 fitted well with the Langmuir model and the adsorption kinetics could be well described by the pseudo-second-order rate model. The results revealed that the maximum adsorption capacity was $93.63 \mathrm{mg} / \mathrm{g}$. The solution $\mathrm{pH}$, reaction time, biosorbent dosage and initial lead(II) concentration highly influenced the lead bioremoval rate. Moreover, EPL01 was used five times without any deterioration in adsorption capacity. The results pointed out that isolate endophyte L01 could potentially reduce aqueous lead concentration.

Keywords: Endophytes, Arsenic hyperaccumulator, Biosorption, Lead(II).

\section{INTRODUCTION}

Lead(II) is widely detected as poisonous heavy metal pollution in natural aquatic environment ${ }^{1,2}$, which can enter and finally accumulate in the human body through drinking water ${ }^{3}$. Numerous studies indicate health problems, such as nephropathy, abdominal pain, anaemia and intertility were of great correlation with lead concentration in human tissues ${ }^{4,5}$. Most of the lead pollution were released from industrial wastewater, facing the growing public concerns. Hence, it is imperative to substantially reduce lead concentration in industrial effluent.

Up to now, scientists have developed various technologies i.e. membrane filtration ${ }^{6}$, ion-exchange ${ }^{7}$ precipitation $^{8}$ and physical adsorption ${ }^{9}$ to remove aquatic lead(II). These technologies have been reported to efficiently eliminate lead contamination to a certain extent, but their application has been limited by the high cost of the continuous consumables needed for the removal process and the requirement for external auxiliary energy ${ }^{10-13}$. Therefore, new technologies for the effective elimination of lead pollutants, without the requirement of large amount of consumables or powerful external source, are desirable. Recently, biosorption has attracted growing attention as an economical, eco-benign and efficient technology for aqueous lead(II) removal. The most significant advantage is it can utilize biosorbents like yeast ${ }^{14}$, algae $\mathrm{e}^{16,17}$ and plant tissue ${ }^{18}$ from agricultural wastes and plants, which poses little adverse effect on natural environment and little burden on chemical material synthesis as sorbents. As such, obtaining the satisfactory biosorbents that are highly efficient for lead(II) removal become the critical factor for this technology to be successfully harnessed.

Endophytes are non-pathogenic microbes living inside plants that colonize the internal tissues of plants without showing any external sign of infection or negative impact on the hosts. Due to the hyperaccumulation ability of endophytes isolated from a heavy metal hyperaccumulator, the host plants can endure high level of a particular heavy metal ${ }^{19,20}$. Most recently, it have been demonstrated that endophytes itself can manifest a good performance as biosorbents on heavy metals pollution remediation, which in certain ways, exhibit some unique advantages over the traditional methods ${ }^{21}$.

The objective of this study was to isolate endophyte L01 (EPL01) from Pteris cretica (a plant known to show high resistance towards arsenic) for removal of lead(II) from water. The effect of solution $\mathrm{pH}$, reaction time, biosorbent dosage and initial concentration of lead(II) on the adsorption process were investigated. To our best of knowledge this is the first study that utilizes an endophytes to absorb heavy metal of different species viz. arsenic endophyte for removal of lead(II). 
EXPERIMENTAL

Isolation and identification of EPL01: The Pteris cretica plants were transplanted from a realgar mine in Shimen county, Hunan province, China. The plants were washed with tap water for removal of mud and then divided into portions of leaf, stem and root. These parts were sterilized by $70 \%$ ethanol and $0.1 \%$ $(\mathrm{m} / \mathrm{v}) \mathrm{HgCl}_{2}$ solution. With the addition of an appropriate amount of PBS buffer $\left(\mathrm{NaH}_{2} \mathrm{PO}_{4} / \mathrm{Na}_{2} \mathrm{HPO}_{4}, \mathrm{pH}=7.4\right)$ solution, each portion was ground into pulp. The prepared plant segments were inoculated onto agar plates and incubated at $303 \mathrm{~K}$ for 7 days.

The genomic DNA of the endophyte bacterium EPL01 was extracted and 16r DNA was amplified in polymerase chain reaction (PCR) using genomic DNA as template and as fungus universal primers (Sequence Forward Primer (27F): 5'-AGAGTTTGATCCTGGCTCAG-3' and Sequence Reverse Primer (1492R): 5'-TACGGCTACCTTGTTACGACT T-3'). Amplification was performed for 30 PCR cycles with annealing at $328 \mathrm{~K}$ for $30 \mathrm{~s}$. The amplified DNA was purified using the Agarose Gel DNA Purification Kit and sequencing was performed at Shanghai Invitrogen Biotechnology Co. LTD. The 16S rDNA sequence was compared against the GenBank database using the NCBI Blast program.

Study of arsenic (III) and lead (II) resistance: The endophyte bacterium EPL01 was inoculated onto an agar solid culture medium containing arsenic(III) and lead(II) of certain concentrations. The growth condition of EPL01 was examined after a period of 3-7 days.

Preparation of biosorbent: The bacterium EPL01 was incubated in the nutrient broth medium at $303 \mathrm{~K}$ for 3 days. Then, the mycelia were separated from the nutrient medium by centrifugation $(10000 \mathrm{rpm}$ ) for $10 \mathrm{~min}$ and inactivated at $394 \mathrm{~K}$ for $20 \mathrm{~min}$. The inactivated mycelia were then washed several times with purified water (purified by a Milli-Q water system (Bedford, America)). The biosorbent was dried in oven at $333 \mathrm{~K}$ for $24 \mathrm{~h}$ and crushed and sieved (120 mesh size) before use.

Preparation of reagents and medium: All the biological reagents were bought from Shuangxuan Biological Reagents Enterprise, Beijing. The nutrient broth medium applied in fostering bacterium was that commonly used in bacterium incubation: $3 \mathrm{~g}$ beef extract, $10 \mathrm{~g}$ peptone, $5 \mathrm{~g} \mathrm{NaCl}, 1 \mathrm{~L}$ purified water. To solidify the medium, $2 \%$ agar was added. The $\mathrm{pH}$ value of medium was adjusted to 7.2-7.4.

All the chemical reagents were of analytical grade and provided by Shantou Xilong Chemical Co., Ltd. (Shantou, China). A stock solution of lead(II) was prepared by dissolving an appropriate amount of anhydrous $\mathrm{Pb}\left(\mathrm{NO}_{3}\right)_{2}$ in $100 \mathrm{~mL}$ deionized water. The lead(II) solutions of various concentrations were obtained through diluting the stock solution. To ensure the accurate determination of heavy-metal concentrations, the testing solution was diluted into the linear detection range of the equipment if needed. The $\mathrm{pH}$ of the solution was adjusted to a designed value (1-6 in this work) by adding aqueous $\mathrm{HNO}_{3}(0.1 \mathrm{~mol} / \mathrm{L})$ or $\mathrm{NaOH}(0.1 \mathrm{~mol} / \mathrm{L})$.

Analytical technique: The $\mathrm{pH}$ of solution was determined by using a pH electrode (pHSJ-3F Shanghai, China). The lead(II) concentration in a solution was determined using an AAS-
990 atomic absorption spectrophotometer (Puxitongyong, Beijing). The hollow cathode lamp was operated at $2 \mathrm{~mA}$ and the analytical wavelength was set at $283.3 \mathrm{~nm}$.

Biosorption and regeneration of EPL01: The biosorption experiments were performed by adding the biosorbent into lead(II) solutions (20,50, $100 \mathrm{mg} / \mathrm{L}$, respectively) and then shaking the mixture using a thermostatic oscillator for a designated period of time (denoted as contact time hereinafter). After shaking a certain contact time, the biosorbent was filtered out and the filtrate was analyzed using an atomic absorption spectrophotometer. The biosorbent was examined using energy dispersive spectrometry (EDS) to characterize lead adsorption. The effect of initial $\mathrm{pH}$ and biosorbent dosage were investigated within the $\mathrm{pH}$ value range of 1-6 and dosage range of 1-3 g/L, respectively.

The kinetics of biosorption was investigated at initial lead(II) concentration of 20, 50 and $100 \mathrm{mg} / \mathrm{L}$, respectively. The adsorbed amount $(\mathrm{mg} / \mathrm{g})$ of lead(II) $\left(\mathrm{q}_{\mathrm{t}}\right)$ was calculated according to the following equation:

$$
\mathrm{q}_{\mathrm{t}}=\frac{\left(\mathrm{C}_{0}-\mathrm{C}_{\mathrm{t}}\right) \mathrm{V}}{\mathrm{m}}
$$

$\mathrm{C}_{0}$ is the initial lead concentration (mg/L), $\mathrm{C}_{\mathrm{t}}$ is the lead concentration $(\mathrm{mg} / \mathrm{L})$ at any time $\mathrm{t}$, and $\mathrm{m}$ is the biosorbent dosage (g).

The regeneration experiments were conducted with $1 \mathrm{~g} / \mathrm{L}$ of biosorbent and the solution $\mathrm{pH}$ value was adjusted to 5 . After contact time for $2 \mathrm{~h}$, the biosorbent was extracted by centrifugation and then washed three times with distilled water to remove residual lead(II). Afterward, the extracted solid was dissolved in $10 \mathrm{~mL} \mathrm{HNO}_{3}$ solution $(10 \mathrm{mM})$ by shaking for $1 \mathrm{~h}$. Then the biosorbent was extracted again by filtration and the filtrate was analyzed. The biosorbent was deionized waterwashed until the eluent $\mathrm{pH}$ was 5 before next sequential experiment. The adsorption-desorption cycle was repeated for a total of five times.

\section{RESULTS AND DISCUSSION}

The endophyte EPL01 was isolated from the leaf of arsenic hyperaccumulator Pteris cretica. The result of the $16 \mathrm{~S}$ rDNA gene sequence analysis confirmed that it was Bacillus sp.. The results of metal resistance experiments indicated that the resistance of EPL01 towards arsenic (III) and lead(II) were about 80 and $5 \mathrm{mmol} / \mathrm{L}$, respectively. Similar observation was reported when Luo et al. ${ }^{21}$ investigated endophytic bacterium LRE07.

With lower maximum resistance concentration, however, EPL01 exhibited much better adsorption capacity for lead(II) than that for arsenic(III) under the present experimental condition ( $\mathrm{pH}=6)$. In fact, arsenic(III) adsorption on EPL01 was barely observed. EDS analysis was employed to examine the EPL01 sample before and after the lead(II) adsorption experiment. Fig. 1 shown that the weight ratio of carbon and oxygen of the original EPL01 sample was 32.10 and 67.90 wt $\%$, respectively. After the adsorption, due to the added weight of adsorbed lead (55.24 wt \%), the percentage of carbon and oxygen dropped to 12.34 and 32.42 wt \%, respectively, confirming the great adsorption capacity of EPL01 for lead (Fig. 1). 


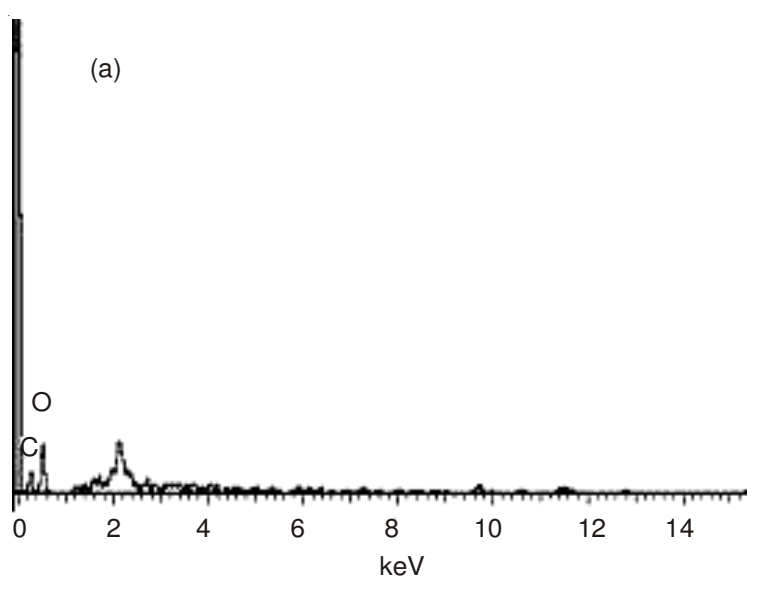

(b)

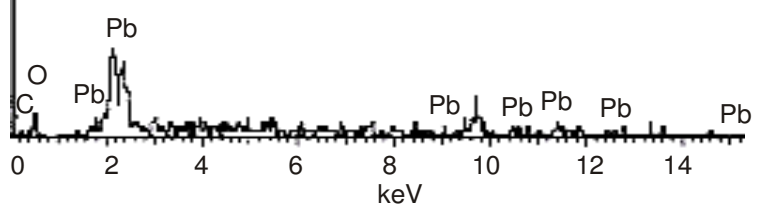

Fig. 1. EDS spectra of endophyte bacterium EPL01 (a) before and (b) after adsorption

The adsorption capacity towards lead(II) was promoted by the interaction between particle surface and dissolved cation which in this case was determined by solution $\mathrm{pH}$. Gram-stain test results indicate that EPL01 was Gram-negative bacteria and the isoelectric point of the bacteria surface was about $\mathrm{pH}$ 4-5. The surface of Gram-negative bacteria is positively charged when the solution $\mathrm{pH}$ value is lower than 4-5 and is negatively charged when the $\mathrm{pH}$ value raises above 4-5. Previous study reported that arsenic(III) presents mainly in the form of $\mathrm{H}_{3} \mathrm{AsO}_{3}$ when the solution $\mathrm{pH}$ value is below $9.1^{23}$. Therefore, the arsenic species $(\mathrm{pH}=6)$ appeared to show electroneutrality at present experimental conditionand hence manifested little electrostatic attraction with EPL01 surface, resulting little adsorption as observed. However, the electrostatic attraction between lead(II) cation and negatively charged EPL01 surface rendered significant metal adsorption.

Effect of initial pH: The $\mathrm{pH}$ value of a solution always has an effect on surface charging of an adsorbent is well known. In the present study, we observed that the $\mathrm{pH}$ of the aqueous solutions pose a critical effect on the adsorption process. We evaluated the effect of $\mathrm{pH}$ on the biosorption of lead(II) at $303 \mathrm{~K}$ for $2 \mathrm{~h}$, having the $\mathrm{pH}$ values regulated in the 1-6 range (concentration of lead(II) $=20,50$ and $100 \mathrm{mg} / \mathrm{L}$; biosorbent dosage $=1 \mathrm{~g} / \mathrm{L}$ ). As shown in Fig. 2, biosorption was hardly observed for a $\mathrm{pH}$ less than 2 . With increase of initial $\mathrm{pH}$ from 2 to 4 , there was sharp rise of biosorption capacity. When $\mathrm{pH}$ is above 4 , the rise of biosorption capacity became slow. The phenomenon could be explained by the fact that when the $\mathrm{pH}$ of the solution is below 2, EPL01 is surrounded by a large number of hydrogen ions. The protons and lead(II) ions compete for the same adsorption sites, so the adsorption capacity of

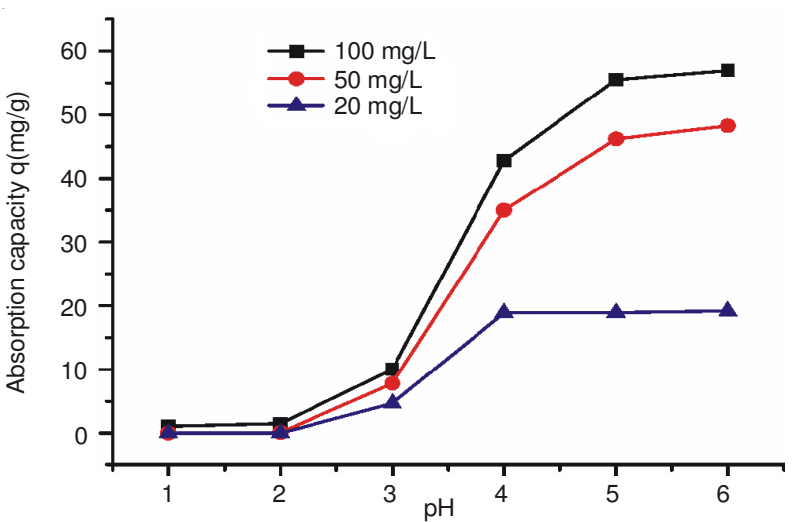

Fig. 2. Effect of pH on lead(II) biosorption on EPL01 at lead(II) concentration of 20,50 and $100 \mathrm{mg} / \mathrm{L}$, (dosage: $1 \mathrm{~g} / \mathrm{L}$, contact time: $2 \mathrm{~h}$, temperature: $303 \mathrm{~K}$ )

lead(II) is low when $\mathrm{pH}$ is below 2 . With rise of the $\mathrm{pH}$, the deprotonation of acid functional groups such as carboxyl and phosphonate strengthens and the attraction between negatively charged biomass and positive metal ions increases; subsequently there is rise of biosorption capacity with increasing $\mathrm{pH}$.

Adsorption kinetics: As displayed in Fig. 3a, the rate of adsorption was fast within the first $10 \mathrm{~min}$ and then became slow in the later stage. At low lead(II) concentration such as 30 and $50 \mathrm{mg} / \mathrm{L}$, it took $10 \mathrm{~min}$ to reach adsorption equilibrium; at lead(II) concentration of $100 \mathrm{mg} / \mathrm{L}$, it took $25 \mathrm{~min}$ to reach adsorption equilibrium. The amount of lead adsorbed at equilibrium reflects the adsorption capacity of biosorbent as there is no further change in lead adsorption with time.

Kinetic modeling is a useful approach to understand the mechanism and reaction rate of an absorbate-biosorbent system. In this study, we adopted the pseudo-first-order rate equation and the pseudo-second-order rate equation. The pseudo-firstorder kinetics equation ${ }^{24}$ is expressed as

$$
\ln \left(\mathrm{q}_{\mathrm{e}}-\mathrm{q}_{\mathrm{t}}\right)=\mathrm{K}_{1} \mathrm{t}+\ln \mathrm{q}_{\mathrm{e}}
$$

where $\mathrm{q}_{\mathrm{e}}$ is the amount of adsorbate at equilibrium (mg/g), $\mathrm{q}_{\mathrm{t}}$ is the amount of adsorbate at any time $(\mathrm{mg} / \mathrm{g})$ and $\mathrm{K}_{1}$ is adsorption constant $\left(\mathrm{min}^{-1}\right)$. The values of $\mathrm{K}_{1}$ were calculated from the slope of " $\ln \left(\mathrm{q}_{\mathrm{e}}-\mathrm{q}_{\mathrm{t}}\right)$ versus $\mathrm{t}$ " plots (Fig. 3b). The correlation coefficients $\left(\mathrm{R}^{2}\right)$ were also calculated. All the parameters are depicted in Table- 1 . The $\mathrm{R}^{2}$ values are relatively low, indicating that the adsorption dynamics of lead(II) on EPL01 does not fit into the pseudo-first-order rate model.

TABLE-1

BIOSORPTION RATE CONSTANTS AND q VALUES OF PSEUDO-FIRST-ORDER AND PSEUDO-SECOND-ORDER KINETIC IN LEAD(II) BIOSORPTION ON EPL01

\begin{tabular}{ccccccccc}
\hline \multirow{2}{*}{$\begin{array}{c}\text { Lead(II) } \\
\text { concen- } \\
\text { tration } \\
(\mathrm{mg} / \mathrm{L})\end{array}$} & $\begin{array}{c}\mathrm{q}_{\mathrm{e}, \text { exp }} \\
(\mathrm{mg} / \mathrm{g})\end{array}$ & \multicolumn{3}{c}{$\begin{array}{c}\text { Pseudo-first- } \\
\text { order kinetic }\end{array}$} & \multicolumn{4}{c}{$\begin{array}{c}\text { Pseudo-second- } \\
\text { order kinetic }\end{array}$} \\
\cline { 3 - 8 } & $\begin{array}{c}\mathrm{q}_{\mathrm{e}, \mathrm{cal}} \\
(\mathrm{mg} / \mathrm{g})\end{array}$ & $\begin{array}{c}\mathrm{K}_{1} \\
\left(\mathrm{~min}^{-1}\right)\end{array}$ & $\mathrm{R}^{2}$ & $\begin{array}{c}\mathrm{q}_{\mathrm{e}, \mathrm{cal}} \\
(\mathrm{mg} / \mathrm{g})\end{array}$ & $\begin{array}{c}\mathrm{K}_{2} \\
(\mathrm{~g} / \mathrm{mg} / \mathrm{min})\end{array}$ & $\mathrm{R}^{2}$ \\
50 & 19.5 & 0.551 & 0.0194 & 0.486 & 19.4 & 0.545 & 1.000 \\
100 & 46.5 & 4.13 & 0.0183 & 0.563 & 45.9 & 0.0641 & 1.000 \\
& 55.0 & 7.78 & 0.0330 & 0.650 & 54.8 & 0.0456 & 0.9999 \\
\hline
\end{tabular}

$\mathrm{q}_{\mathrm{e}, \text { exp }}$ : The experimental values of $\mathrm{q}_{\mathrm{e}} ; \mathrm{q}_{\mathrm{e}, \text { cal }}$ : The calculated $\mathrm{q}_{\mathrm{e}}$ values from model

The linear form of pseudo-second-order model is expressed as followed: 


$$
\frac{\mathrm{t}}{\mathrm{q}_{\mathrm{t}}}=\frac{\mathrm{t}}{\mathrm{q}_{\mathrm{e}}}+\frac{1}{\mathrm{~K}_{2} \mathrm{q}_{\mathrm{e}}^{2}}
$$

where $\mathrm{K}_{2}$ is the constant rate of pseudo-second-order $(\mathrm{g} / \mathrm{mg}$ $\left.\mathrm{min}^{-1}\right)$. The plot of $\mathrm{t} / \mathrm{q}_{\mathrm{t}}$ versus $\mathrm{t}$ would give a linear relationship from which, $\mathrm{q}_{\mathrm{e}}$ and $\mathrm{K}_{2}$ can be obtained from the slope and intercept of the plot, respectively (Fig. 3c). The $\mathrm{K}_{2}, \mathrm{q}_{\mathrm{e}}$ and $\mathrm{R}^{2}$ determined from the model are listed in Table- 1 . The $\mathrm{R}^{2}$ values are found to be approximately 1 , indicating that the adsorption process of lead(II) on EPL01 followed a pseudo-second-order kinetic model. Furthermore, the experimental $\mathrm{q}_{\mathrm{e}}\left(\mathrm{q}_{\mathrm{e}}\right.$,exp $)$ data fit well with the calculated $\mathrm{q}_{\mathrm{e}}\left(\mathrm{q}_{\mathrm{e}, \mathrm{cal}}\right)$ of the pseudo-second-order kinetic model.

Adsorption isotherm: The adsorption isotherm of lead(II) on EPL01 is shown in Fig. 4a. As suggested before, the initial concentration of metal ions in the solution plays a key role as a driving force to overcome the mass transfer resistance between the aqueous and solid phases ${ }^{20}$. It is hence expected that there is increase of adsorption capacity with rise of initial lead(II) concentration. It can be seen from Fig. 3a that the adsorption capacity indeed increases with rise of lead(II) concentration. The results indicated that EPL01 can be well adopted in treating wastewaters of high lead(II) concentration.

The adsorption data are fitted into the two most commonly used isotherms, viz. Langmuir and Freundlich. The general forms of the two models could be described as follows ${ }^{25}$ :

Linear form of Langmuir equation:

$$
\frac{\mathrm{C}_{\mathrm{e}}}{\mathrm{q}_{\mathrm{e}}}=\frac{1}{\mathrm{~b} \cdot \mathrm{q}_{\max }}+\frac{\mathrm{C}_{\mathrm{e}}}{\mathrm{q}_{\max }}
$$

where $\mathrm{q}_{\max }$ is the maximum amount of metal ions adsorbed per unit weight of adsorbent for the formation of a monolayer of adsorbate on the surface, $b$ represents the Langmuir constant that is related to the affinity of the binding sites, $C_{e}$ is the concentration of metal ions at equilibrium and qe is the amount of metal ions adsorbed at equilibrium. The Langmuir model assumes that the surface of biosorbent is homogeneous and covered with a monolayer of adsorbate.

Linear form of Freundlich equation:

$$
\ln \mathrm{q}_{\mathrm{e}}=\ln \mathrm{K}+\frac{1}{\mathrm{n}} \ln \mathrm{C}_{\mathrm{e}}
$$

where $\mathrm{K}$ and $\mathrm{n}$ are Freundlich constants indicating adsorption capacity and adsorption intensity, respectively.

The plots of the Langmuir and Freundlich equations are shown in Fig. 4b and 4c, respectively and the related parameters are shown in Table-2. It can be seen that the Freundlich isotherm does not fit the experimental data as good as the Langmuir model, as reflected by the values of the corresponding constants and correlation coefficients. It is worth pointing out that the theoretical maximum adsorption capacity obtained based on the slope of Langmuir plot is $93.63 \mathrm{mg} / \mathrm{g}$, suggesting that EPL01 has good potential for lead(II) removal from waste waters.

\begin{tabular}{ccccccc}
\multicolumn{6}{c}{ TABLE-2 } \\
LANGMUIR AND FREUNDLICH ISOTHERM \\
PARAMETERS OF LEAD(II) BIOSORPTION ON EPL01 \\
\hline \multirow{2}{*}{ Biosorbent } \\
\cline { 2 - 7 } & $\mathrm{b}$ mM) & $\left.\mathrm{q}_{\max } \mathrm{mg} / \mathrm{g}\right)$ & $\mathrm{R}^{2}$ & $\mathrm{n}$ & $\mathrm{K}$ & $\mathrm{R}^{2}$ \\
\hline EPL01 & 0.021 & 93.6 & 0.99 & 7.39 & 34.6 & 0.94 \\
\hline
\end{tabular}

Effect of dosage and reusability: The cost of a biosorbent is one of the major concerns in its application. Whether a biosorbent is economical to use depends on the effective dosage and reusability of the biosorbent. The effect of absorbent dosage is illustrated in Fig. 5. It can be seen that there is decrease in
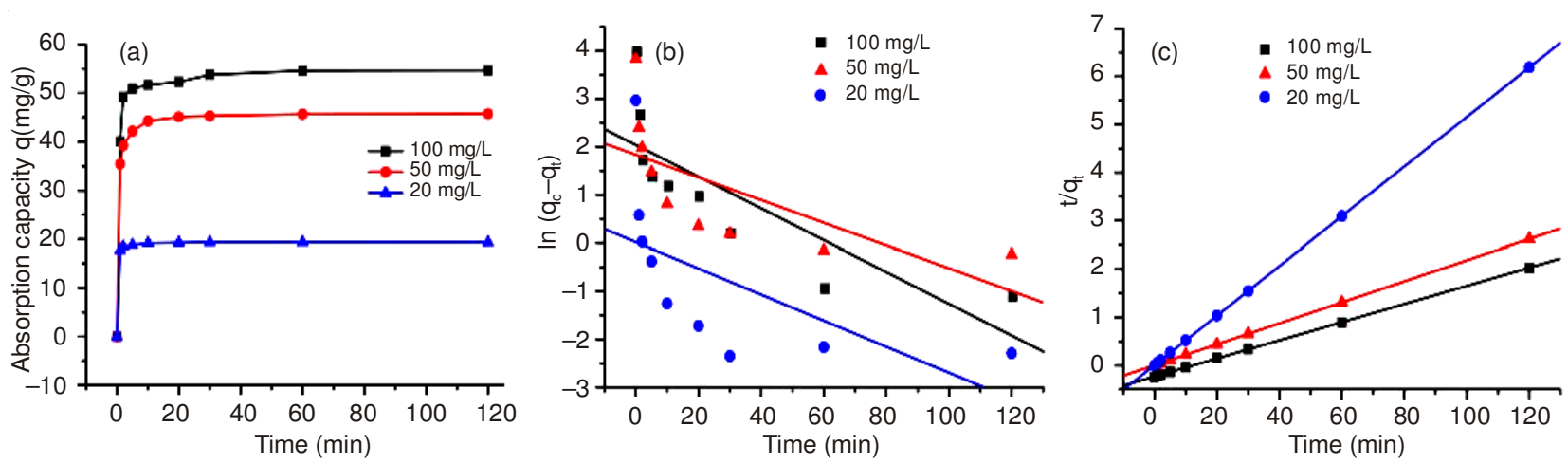

Fig. 3. (a) Adsorption kinetics of lead (II) on EPL01 at lead (II) concentration of 20, 50 and 100 mg/L, (b) linear pseudo-first-order plot and (c) linear pseudo-second-order plot
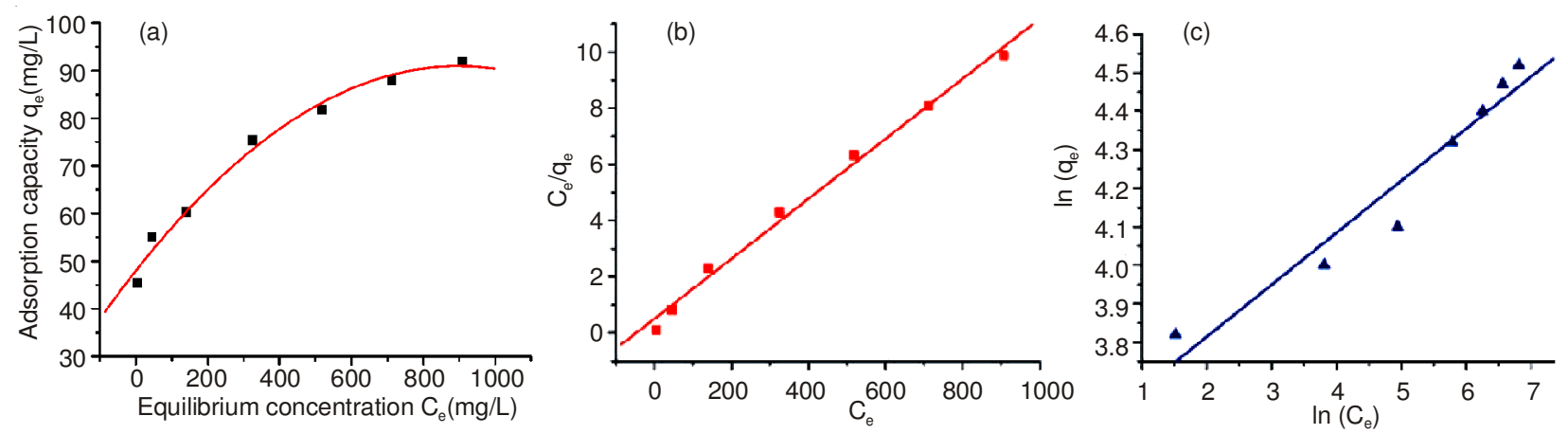

Fig. 4. (a) Adsorption isotherm of lead(II) adsorption on EPL01, (b) linear Langmuir plot and (c) linear Frenudlich plot 
adsorption capacity with rise of adsorbent dosage from 1 to 3 g/L. Similar phenomena were observed when Citrobacter strain MCMB-181 and EF LSE10 were employed as biosorbents to remove lead, cadmium and zinc $^{20,26}$. The possible explanation for the higher biosorption capacity at a lower biosorbent dosage is that the number of binding sites available for adsorption was determined by the dose of biomass added to the solution and an increase in metal-to-adsorbent ratio decreases with increasing dosage $\mathrm{e}^{20}$.

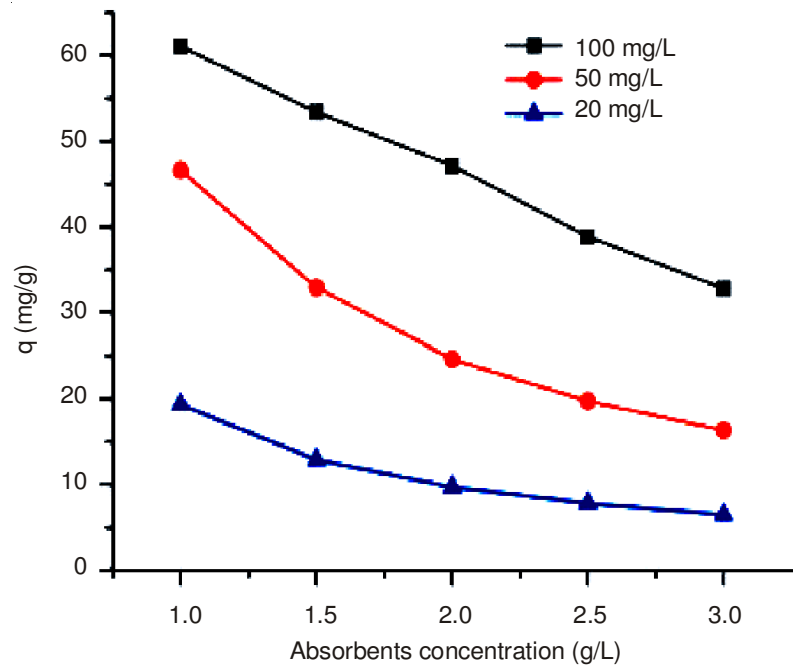

Fig. 5. Effect of biosorbent dosage on lead(II) biosorption on EPL01 at lead (II) concentration of 20, 50 and $100 \mathrm{mg} / \mathrm{L}$. (pH: 5, contact time: $2 \mathrm{~h}$, temperature: $303 \mathrm{~K}$ )

The reusability of biosorbent EPL01 was assessed using $10 \mathrm{mM} \mathrm{HNO}_{3}$ to elute the biosorbent. As shown in Fig. 6, there is little change in adsorption capacity of EPL01 in five cycles of testing and the adsorption capacity of the final cycle is well over $90 \%$ of that of the initial cycle. Based on the results of effective dosage and reusability studies, it is clear that the EPL01 biosorbent is economical to use in the treatment of wastewater for lead(II) removal.



Fig. 6. Recyclability of biosorbent in lead(II) biosorption [lead(II) concentration $=20,50$ and $100 \mathrm{mg} / \mathrm{L}]$

\section{Conclusion}

The endophyte bacterium EPL01 was isolated from arsenic hyperaccumulator plant Pteris cretica. The EPL01 biosorbent shows high potential in the removal of lead(II) ions from wastewater. In this work, an endophyte bacterium isolated from a hyperaccumulator plant of a certain heavy metal can have good adsorption capacity for the ions of another heavy metal. The EPL01 biosorbent is economical to use because of the low effective dosage and high reusability of the biosorbent.

\section{ACKNOWLEDGEMENTS}

This work was financially supported by the Natural Science Foundation of China (50978132, 51178213, 51308278), Program for New Century Excellent Talents in University (NCET-11-1004) and Jiangxi Provincial Funds for Young Scientists (20112BCB23016). Thanks are also due to Prof. C.T. Au of the Hong Kong Baptist University for helpful advices.

\section{REFERENCES}

1. A.R.A. Usman, S.S. Lee, Y.M. Awad, K.J. Lim, J.E. Yang and Y.S. Ok, Chemosphere, 87, 872 (2012).

2. G.D. Vukovic, A.D. Marinkovic, S.D. Škapin, M.Đ. Ristic, R. Aleksic, A.A. Peric-Grujic and P.S. Uskokovic, Chem. Eng. J., 173, 855 (2011).

3. S.S. Gupta and K.G. Bhattacharyya, Appl. Clay Sci., 30, 199 (2005).

4. A. Agrawal, K.K. Sahu and B.D. Pandey, J. Colloid Interf. Sci., 281, 291 (2005).

5. V.J.P. Vilar, F. Sebesta, C.M.S. Botelho and R.A.R. Boaventura, Proc. Biochem., 40, 3276 (2005).

6. R. Sabry, A. Hafez, M. Khedr and A. El-Hassanin, Desalination, 212, 165 (2007).

7. J.F.S.S. Costa, V.J.P. Vilar, C.M.S. Botelho, E.A.B. da Silva and R.A.R. Boaventura, Water Res., 44, 3946 (2010).

8. G. Macchi, M. Pagano, M. Santori and C. Tiravani, Water Res., 27, 1511 (1993).

9. S.V. Dimitrova, Water Res., 36, 4001 (2002).

10. A. Salem and R.A. Sene, Chem. Eng. J., 174, 619 (2011).

11. J.O. Esalah, M.E. Weber and J.H. Vera, Sep. Sci. Technol., 18, 25 (2000).

12. J.L. Wang and C. Chen, Biotechnol. Adv., 27, 195 (2009).

13. J. Acharya, J.N. Sahu, C.R. Mohanty and B.C. Meikap, Chem. Eng. J., 149, 249 (2009).

14. R.P. Han, H.K. Li, Y.H. Li, J.H. Zhang, H. Xiao and J. Shi, J. Hazard. Mater. B, 137, 1569 (2006).

15. L.P. Deng, Y.Y. Su, H. Su, X.T. Wang and X.B. Zhu, J. Hazard. Mater., 143, 220 (2007).

16. V.K. Gupta and A. Rastogi, Biointerfaces, 64, 170 (2008).

17. M.M. Montazer-Rahmati, P. Rabbani, A. Abdolali and R.A. Keshtkar, J. Hazard. Mater., 185, 401 (2011).

18. N.M. Ibrahim, W.S.W. Ngah, M.S. Norliyana, W.R.W. Daud, M. Rafatullah, O. Sulaiman and R. Hashim, J. Hazard. Mater., 182, 377 (2010).

19. S.H. Wei, Q.X. Zhou and X. Wang, Chin. Sci. Bull., 49, 2568 (2004).

20. X. Xiao, S.L. Luo, G.M. Zeng, W.Z. Wei, Y. Wan, L. Chen, H. Guo, Z. Cao, L. Yang, J. Chen and Q. Xi, Bioresour. Technol., 101, 1668 (2010).

21. S.L. Luo, Y. Wan, X. Xiao, H.J. Guo, L. Chen, Q. Xi, G. Zeng, C. Liu and J. Chen, Appl. Microbiol. Biotechnol., 89, 1637 (2011).

22. Q.Y. Zhou and T.Y. Gao, The Microorganism of Environmental Engineering, Higher Education Press, Beijing (2000).

23. B.E. Reed, R. Vaughan and L. Jiang, J. Environ. Eng., 126, 869 (2000).

24. C.C.V. Cruz, A.C.A. da Costa, C.A. Henriques and A.S. Luna, Bioresour. Technol., 91, 249 (2004).

25. X. Luo, Y. Zhan, Y. Huang, L. Yang, X. Tu and S. Luo, J. Hazard. Mater., 187, 274 (2011).

26. P.R. Puranik and K.M. Paknikar, Biotechnol. Prog., 15, 228 (1999). 